\title{
Are climate models that allow better approximations of local meteorology better for the assessment of hydrological impacts? A statistical analysis of droughts
}

Antonio-Juan Collados-Lara ${ }^{1}$, David Pulido-Velazquez ${ }^{1}$, Juan-de-Dios Gómez-Gómez ${ }^{2}$, Eulogio

5 Pardo-Igúzquiza ${ }^{3}$

${ }^{1}$ Spanish Geological Survey (IGME), Urb. Alcázar del Genil, 4. Edificio Zulema, Bajo, 18006 Granada, Spain

${ }^{2}$ Spanish Geological Survey (IGME), La Calera, 1, 28760 Tres Cantos, Spain

${ }^{3}$ Spanish Geological Survey (IGME), Ríos Rosas, 23, 28003 Madrid, Spain

Correspondence to: Antonio-Juan Collados-Lara (ajcollados@gmail.com)

10 Abstract. This work studies the benefit of using more reliable local climate scenarios to analyse hydrological impacts. It assumes that more reliable local scenarios are defined with the statistically corrected Regional Climate Model (RCM) simulations when they provide better approximations to the historical basic and drought statistics. The paper analyses if the best solutions in terms of their approximation to the local meteorology also provide the best hydrological assessments. A classification of the corrected RCM simulations attending to both approximations is performed. It has been applied in the

15 Cenajo Basin (southeast Spain), where we demonstrate that the best approximations of the historical meteorological statistics provide also the best approximations of the hydrology ones. The selected RCMs were used to generate future (2071-2100) local scenarios under the RCP 8.5 emission scenario. The two selected RCMs predict significant changes of mean precipitation (-31.6 and $-44.0 \%)$ and mean temperature $(+26.0$ and $+32.2 \%)$. They also predict higher frequency (from 5 events in the historical period to 20 and 22 in the future), length (4.8 to 7.4 and 10.5 months), magnitude (2.53 to 6.56 and $9.62 \mathrm{SPI}$ ) and intensity ( 0.48 to 1.00 and $0.94 \mathrm{SPI})$ of extreme meteorological droughts.

\section{Introduction}

During the last decades large scale intensive droughts have been observed in all continents around the globe (Kogan and Guo, 2016). In Europe the 2003 and 2015 droughts may be regarded as the most extreme droughts over the last 250 years (Hanel et al., 2018). In Spain the 2005 drought was the most marked since records began (Vicente-Serrano et al., 2017).

25 In order to assess different types of droughts several indices have been proposed in the literature since 1950 by studying different climatic and hydrological variables (Heim, 2002; Mishra and Sight, 2010; Pedro-Monzonis et al., 2015). For instance, we have Palmer Drought Severity Index (PDSI) (Palmer, 1965), Crop Moisture Index (CMI) (Palmer, 1968), Standardized Precipitation Index (SPI) (McKee et al., 1993), Soil Moisture Drought Index (SMDI) (Hollinger et al., 1993), Vegetation Condition Index (VCI) (Liu and Kogan, 1996). From their name we can deduce that some of them were defined to analyse specific characteristics, such as length, magnitude or intensity, and types of droughts (meteorological, agricultural 
or hydrological droughts). Some of these indices can be generalized to analyse most of the characteristics of the different types of droughts, (as for example the SPI, Mckee et al., 1993, 1995), and their propagation.

In most of the water scarce areas droughts will be intensified in the future due to global change, which is associated with an increment in the occurrence of extreme events. The impact of global change on droughts is a major concern of climate change. The Mediterranean basin is one of the areas that will be most affected by droughts in the future (Tramblay et al., 2020). In addition, the latest climate change studies expect significant decreases in resources in the Mediterranean basins, with significant environmental, economic and social impacts (Cramer et al., 2018). Although in the last years the number of papers studying this issue has grown (Marcos-Garcia et al., 2017; Collados-Lara et al., 2018), we still need to advance on the assessment (through appropriate indices and techniques) of this important social issue (Mishra and Sight, 2011). Some authors directly use Regional Climatic Model (RCM) simulations to assess future droughts (e.g. Lloyd-Hughes et al., 2013; Zhang et al., 2017) in water resources systems, other works show cases with significant bias between the historical and the modelled values (Cook et al., 2008; Seager et al., 2008), which requires further analysis and corrections.

Different approaches [e.g. delta change (Pulido-Velazquez et al., 2018) or bias correction (Collados-Lara et al., 2019)] can be used to downscaling RCMs simulations according to the local historical climatology (Collados-Lara et al., 2018). They

45 use different statistical correction techniques [e.g. first and second moment correction, regression (Collados-Lara et al., 2020) or quantile mapping (Gudmundsson et al., 2012)]. The different approaches produce different approximations of the statistics of the historical period depending on the RCM simulations. They also show a wide range of future corrected simulations that reveals the uncertainty related with the climatic models and their propagation (Pardo-Igúzquiza et al., 2019; Pulido-Velazquez et al., 2018). Hence, using several RCMs is recommended to assess impacts of climate change.

50 The generated scenarios can be used to define a set of individual local projections, which take into account the uncertainty, or to create ensembles of them, which define more robust climate scenarios than those based on a single projection (AEMET, 2009). In both cases a classification of RCM simulations according to its reliability in terms of their capacity to approximate historical meteorological statistics is needed. Depending on the objective of the study the reliability classification should consider different statistics. For droughts assessment, in addition to the basic statistics (mean, standard deviation, and asymmetry coefficient), droughts statistics (e.g. frequency, duration, magnitude, and intensity) should be studied (Collados-Lara et al., 2018). In literature few works analyse the reliability of RCMs considering meteorological droughts. As far as we know, there are not studies that analyse if climate models that provide the best approximations of the local historical meteorology provide also better assessments of the hydrological impacts. In these cases, the generated local climatic scenarios have to be propagated by using hydrological models (Senent-Aparicio et al., 2018; Pardo-Igúzquiza et al., 60 2017).

The main objective of this paper is to answer the following question: Are climate models that allow better approximations of local meteorology better for the assessment of hydrological impacts? It is a question that will be answered by a novel approach based on the analyses of basic and drought statistics. We propose a classification method for RCM simulations according to its capacity to generate local climatic scenarios that reproduce the historical period (in terms of basic and 
65 drought statistics). The classification has been done and compared for both, meteorological and hydrological scenarios, considering basic and drought statistics, in order to compare the results for both types of droughts. Based on these analyses, an integrated statistical method is proposed to generate "more reliable" potential future climate scenarios from RCM simulations and historical data. It intends to contribute to a better assessment of future meteorological and hydrological droughts, and is applicable to any case study.

70 The paper is structured as follows. In section 2 we describe the proposed method. Section 3 is focused on the description of the case study and the available data, including historical and climatic simulations. In section 4 and 5 the results and discussion are outlined respectively. Finally, section 6 summarizes the main conclusions of this study.

\section{Methodology}

The steps that define the proposed method are represented in the flow chart showed in Fig. 1. It requires to compile monthly information about historical precipitation, temperature and streamflow within the system, and RCM simulations. Long historical series are needed in order to perform an appropriate statistical analysis of the proposed approaches. Periods of analyses that cover 30 years or even longer are recommended. A statistical analysis is proposed in order to assess the bias between the statistics of the RCM control simulations and the historical scenarios in the case study. If there are significant differences between them, the RCM simulations for the future horizon cannot be directly used to define the future climatic scenarios of the system, and we need to apply some statistical corrections to them.

\subsection{Correction of historical climate scenarios}

We correct the RCM control simulations by applying a bias correction approach. It is based on a transformation function that minimizes the differences between the control simulations and historical scenarios (Shrestha et al., 2017). The statistical transformation was defined by a quantile mapping technique based on empirical quantiles. We used the open-source $\mathrm{R}$ package qmap (Gudmundsson et al., 2012). In this approach the empirical cumulative distribution functions are approximated using tables of the empirical percentiles and the values between the percentiles are approximated by using linear interpolation. If the RCM values are larger than the historical ones used to estimate the empirical cumulative distribution function, the correction found for the highest quantile of the historical period is used (Gudmundsson et al., 2012). This technique has been demonstrated to be better than other simpler ones (first and second moment correction, regression, and quantile mapping using parametric distributions) to correct basic statistics (mean, standard deviation, and asymmetry coefficient) (see Collados-Lara et al., 2018). This is the reason that justifies the selection of quantile mapping (using empirical quantiles) for this study. 


\subsection{Definition of the rainfall-runoff model}

A hydrological balance model is defined to propagate different climatic scenarios (historical, control, corrected control and

futures) in order to assess hydrological series (streamflow series) and their basic and drought statistics. A rainfall-runoff model was calibrated (by minimizing the sum of the squared errors for each month) with the available historical data (Pulido-Velazquez et al., 2008). In this work we applied a Temez model (Témez, 1977) to assess inflow scenarios in the basin. It is a lumped conceptual hydrological model frequently employed in Spanish basins (Escriba-Bou et al., 2017, PerezSanchez et al., 2019). It is formulated by a balance and transfer equations using just four parameters and two storage tanks (representing the soil or unsaturated zone and the aquifer). The potential evapotranspiration, which is required in this model, has been estimated by applying the Thornthwaite method (Thornthwaite, 1948) from temperature data.

\subsection{Classification of RCMs}

An analysis of the goodness of fit for each RCM simulation after applying the statistical correction was performed for the meteorological series, and the hydrological simulations. The accuracy of the model was analysed in terms of basic (mean, standard deviation, and asymmetry coefficient) and drought statistics (frequency, duration, magnitude, and intensity). The meteorological drought analysis was developed by applying the Standard Precipitation index (SPI) (Bonaccorso et al., 2003; Livada and Assimakopoulos, 2007). The statistics of the SPI series are obtained by applying run theory (González and Valdés, 2006; Mishra et al., 2009) for different SPI thresholds. This SPI approach has been also applied to analyse the hydrological droughts. Note that the probability of occurrence of precipitation for the SPI calculation, in the corrected control and future simulations, was obtained using parameters calibrated from the observed series, in order to perform an appropriate comparison (Marcos-Garcia et al., 2017). In order to analyse the benefit of the proposed method to select future climatic scenarios in the assessment of basic and drought statistics, we checked if the local climatic scenarios from RCM simulations that allow better approximations of the meteorology provide better assessments of the hydrological statistics.

We assessed the goodness of fit for each RCM in the reference period by applying the next error index (SE):

$115 \quad \mathrm{SE}=\frac{1}{\left(\frac{1}{\mathrm{~N}} \sum_{1}^{N} \mathrm{~S}_{\mathrm{h}}(\mathrm{N})\right)^{2}} \frac{1}{\mathrm{~N}} \sum_{1}^{N}\left(\mathrm{~S}_{\mathrm{c}}(\mathrm{N})-\mathrm{S}_{\mathrm{h}}(\mathrm{N})\right)^{2}$,

Where $\mathrm{S}$ is the statistic being considered, $\mathrm{N}$ is 12 in the case of basic statistics (number of months in a year) and the number of SPI thresholds considered in the case of droughts statistics, $\mathrm{c}$ is corrected control scenario, and $\mathrm{h}$ is the historical scenario. Note that this index is a mean squared error of the corrected control with respect the historical values which is divided by the square of the mean value of the historical values in order to make comparable it between the different RCMs.

120 This error index was calculated for each basic (mean, standard deviation, asymmetry coefficient) and drought (frequency, length, magnitude, and intensity) statistic and used to classify RCMs according its reliability for the assessment of meteorological and hydrological impacts. For each statistic we classified the RCMs according the following criteria. The RCMs that has a SE lower than 0.0009 (equivalent to a $3 \%$ of relative error) are not penalized. The rest of RCMs are 
penalized proportionally from 1 to 10 being 1 for the lowest SE and 10 for the highest SE. Finally the classification of the

RCMs for the meteorological and hydrological analyses is done by calculating the average of the penalization for all the statistics (basics and droughts).

\subsection{Generation of local future climate scenarios and statistical analysis of results}

The classification of local climatic scenarios from RCM simulations allows us to identify approaches with higher reliability for both meteorological and hydrological statistics. For these RCM simulations we can generate local future climate scenarios by applying the same transformation function used to correct the control simulation to the future simulation series. These scenarios can be used as individual projections that allow us taking into account the uncertainty by considering a set of different RCM simulations. An ensemble of scenarios could be also applied to produce more robust climate scenarios than those based on a single projection. Finally, these future scenarios were analysed in terms of basic and drought statistics, and compared with the historical scenarios to assess the impacts of climate change on meteorology and hydrology.

\section{Case study and data}

The proposed methodology was applied to the Cenajo basin. It is located in southeast of Spain (Fig. 2), within the headwaters basin of the Segura River, which is the main stream of the Segura basin. The main cities of the system are Murcia with a population of around 440,000 habitants, and Alicante with a population of around 330,000. These cities are partially supplied by the Segura River system. The Segura River is also important for agriculture. The main socioeconomic activity is the irrigated agriculture, traditionally concentrated in the alluvial and coastal plains. The main crops are citrus and fruit trees, and also green and other vegetables. This coastal basin is an example of a Mediterranean area with a significant water demand, mainly for irrigation but also for urban supply (with an important seasonal component for the touristic sector), and low availability of resources. In fact, it is a system with significant deficits that needs water transfers from Tagu s Basin and additional supply from desalination plants to meet the existing demands. This is a critical area where climate change will exacerbate these problems by reducing the availability of resources and increasing irrigation requirements. It will also cause an increase in the magnitude and frequency of extreme events, such as droughts.

We used historical climatic data (precipitation and temperature) provided by Spain02 v2 dataset (Herrera et al., 2012) for the period 1972-2001. In this work we performed a lumped analysis in the Cenajo basin. The RCMs were retrieved from the CORDEX project (2013), with a spatial resolution of $0.11^{\circ}$ (approximately $12.5 \mathrm{~km}$ ). The most pessimistic emission scenario (RCP8.5) for the future horizon 2071-2100 was selected for the future projections. For this scenario we analysed nine RCMs corresponding to four different General Circulation Models (GCMs) (see Table1). We also used official monthly natural streamflow data within the Cenajo basin for the historical period 1972-2001 (adopted as reference). These data were taken from the available information coming from the Spanish Ministry of Agriculture, food and environment. 


\section{Results}

155

\subsection{Corrected historical simulations}

The observed differences between the historical series and the control simulation series of precipitation and temperature for the reference period (1972-2001) in terms of basic statistics are large. The relative differences between the historical and the control simulations for the mean yearly precipitation (Fig. 4a) vary from $-5.6 \%$ for RCM5 and $52.8 \%$ for RCM8. In the same way, the distances in standard deviation (Fig. 4c) and asymmetry coefficient (Fig. 4e) are also large. The relative differences between the historical temperature and the control simulations for mean year values (Fig. 5a) vary from $-6.2 \%$ for RCM3 and -39.4\% for RCM5. The differences in temperature standard deviation (Fig. 5c) and asymmetry coefficient (Fig. 5e) are also remarkable. These differences force us to apply the correction approach defined in section 2.1 for all the RCMs considered. The corrected control simulation series presents a very good fit with respect the historical series in terms of basic statistics for precipitation [mean (Fig. 4b), standard deviation (Fig. 4d) and asymmetry coefficient (Fig. 4f)] and for temperature [mean (Fig. 5b), standard deviation (Fig. 5d) and asymmetry coefficient (Fig. 5f)]. The differences between the historical series and the corrected control simulation for the basic statistics are close to zero. It confirms the results obtained by Collados-Lara et al. (2018) when compared different statistical correction techniques. The quantile mapping (with empirical quantiles) technique shows very good results in terms of the basic statistics when RCMs are corrected.

The same analysis of basic statistics was done for the streamflow (Fig. 6). The relative differences between the historical and the control simulations for the mean yearly streamflow (Fig. 6a) vary from $-4.9 \%$ for RCM5 and $125.5 \%$ for RCM8. It also shows very large differences for the standard deviation (Fig. 6c) and the asymmetry coefficient (Fig. 6e). The fit of the corrected control simulation series of streamflow to the historical series is not as good as for precipitation and temperature, but a remarkable improvement is observed. The relative differences for mean streamflow in the case of the corrected control simulation (Fig. 6b) varies from $-1.8 \%$ for RCM2 and $-4.6 \%$ for RCM8. Similar improvements are observed for standard deviation (Fig. 6d) and asymmetry coefficient (Fig. 6f).

In the case of meteorological droughts (calculated from SPI) the bias correction approach clearly improves the fit of the RCM simulation series to the historical series for the four considered statistics (frequency, duration, magnitude and intensity). Note the differences between the left panel of Fig. 7 (control simulation and historical series) and right panel of 
Fig. 7 (corrected control simulation and historical series). For frequency the mean of SE for all the RCMs before the correction is 0.69 and after the correction is 0.23 . For duration, magnitude and intensity these values are respectively 0.51 vs. $0.17,0.88$ vs. 0.30 and 0.38 vs. 0.13 . In the same way, hydrological droughts were studied considering the SPI approach for streamflow. Note that in this case we refer to the Standard Streamflow Index (SSI). Significant improvements are also observed for hydrological droughts (Fig. 8) after the bias correction procedure: frequency (0.63 vs. 0.34), duration ( 0.50 vs. $0.23)$, magnitude ( 0.83 vs. 0.51$)$, and intensity ( 0.48 vs. 0.15$)$.

\subsection{Corrected historical simulations}

The classification of RCMs (after the bias correction procedure) for the meteorology and hydrology considering both basic and drought statistics according to the procedure described in section 2.3 is included in Table 2. The two best corrected RCMs for meteorology (RCM2 and RCM9) are also the two best models for hydrology. There is a correlation between the order classification of corrected RCMs for meteorology and hydrology (Fig. 9) which is higher for higher orders of classification. The regression line in the scatter plot is also closer to the 1:1 line (line in which the same classification order is obtained for both meteorology and hydrology) for higher orders of classification. Therefore, we demonstrated that RCMs that allow better approximations of the meteorology provide better assessments of hydrological impacts.

\subsection{Corrected future local scenarios}

The corrected RCM2 and RCM9, which are the best climate models to reproduce historical meteorology and hydrology, were used to generate local potential scenarios of precipitation and temperature. The rainfall-runoff model was used to propagate the impacts of climate variables to streamflow. In order to compare the historical and the future scenarios basic statistics and drought statistics were analysed for the horizon 2071-2100. The considered RCMs predict significant reductions of mean precipitation (-31.6 and $-44.0 \%$ for RCM2 and RCM9 respectively) and increase of mean temperature (26.0 and $32.2 \%$ for RCM2 and RCM9 respectively) (see Fig. 10a and 10b respectively). The average change in monthly standard deviation of precipitation is -6.2 and $-32.3 \%$ for RCM2 and RCM9 respectively. In the case of temperature these changes are 23.9 and $4.8 \%$. Both RCMs predicts a decrease of the variability in precipitation and an increase of the variability of temperature in the future (see Fig. 10c and 10d respectively). However the expected values of changes are significantly different. Both RCMs also predict significantly different changes in the asymmetry coefficient of series (Fig. 10e and 10f). With respect the hydrology analysis, both RCMs predict significant decreases of streamflow (-43.5 and $57.2 \%$ for RCM2 and RCM9 respectively) (Fig. 11a). In the case of the variability, the RCMs predict a reduction (Fig. 11b). The average change in monthly standard deviation is -26.2 and $-57.5 \%$ for RCM2 and RCM9 respectively. In the case of the asymmetry coefficient both RCMs show an increment with respect the historical scenario (Fig. 11c).

215 Significant changes are also expected for droughts. In the case of the meteorological droughts the first SPI threshold for which droughts periods are detected in the historical scenario is -3.0. In the future scenarios this value is -5.2 and -4.6 for the RCM2 and RCM9 respectively (Fig. 12). The maximum frequency of meteorological droughts in the historical period is 
obtained for the SPI threshold of 0 while in the case of the future scenarios is obtained for -1.1 and -1.9 for the RCM2 and RCM9 respectively. For the threshold of 1.7 of SPI (considered to define extreme droughts in the Droughts Plan of the Segura River basin authority) in the historical period 5 droughts events are detected with a mean length of 4.8 months. The mean magnitude and intensity of these events are 2.53 and 0.48 SPI. In the case of the future scenario of the RCM2 20 droughts events are detected with a mean length, magnitude and intensity of 7.4 months, 6.56 and 1.00 SPI. The case of the future scenario of RCM9 is even more worrying with 22 extreme droughts events which have a mean length, magnitude and intensity of 10.5 months, 9.62 and 0.94 SPI respectively.

In the case of the hydrological droughts the first SSI threshold in which we detected droughts is -2.9 (similar to the meteorological droughts). In the future scenarios this value is -3.9 and -4.2 for the RCM2 and RCM9 respectively (Fig. 13). Note that in the case of the hydrological droughts the minimum SSI in the future scenario is obtained for the RCM9 and in the case of the meteorological droughts the minimum SPI is obtained for the RCM2. However in both cases (meteorological and hydrological) the RCM9 shows higher impacts on the mean length, magnitude and intensity of droughts events.

\section{Discussion}

The selected RCMs simulations cannot be used directly for the case studied due to the detected biases. The relative differences vary in the range -5.6 to $52.8 \%$ for precipitation and -6.2 to $-39.4 \%$ for temperature. It is accepted in scientific community that RCMs must be corrected to adapt them to the local climate conditions (Teutschbein and Seibert, 2012).

In this study we used the quantile mapping based on empirical quantiles technique to perform the bias correction of the

RCMs. A previous comparative analysis of different correction techniques (first moment correction, first and second moment correction, regression, and quantile mapping using distribution and empirical quantiles) demonstrated the higher accuracy of the empirical quantile mapping (Collados-Lara et al., 2018). This technique is able to provide very good results to correct basic statistics (mean, standard deviation and asymmetry coefficient) as we confirmed in this study. However, some authors argue that using simple techniques as linear scaling is sufficient for hydrological analysis at monthly resolution (Shrestha et al., 2017). Others authors assumed that a first and second moment correction is sufficient for hydrological applications (Collados-Lara et al., 2019). This topic is still open to discussion in the scientific community and authors are even developing and testing new techniques [e.g. TIN-Copula (Lazoglou et al., 2020), Markov chains (Liu et al., 2020)].

Another aspect faced in this paper in the generation of local future scenarios is the selection of RCMs. In this work we proposed a method to classify the RCM simulations based on basic and drought statistics of the corrected series. ColladosLara et al. (2018) proposed a multi-criteria analysis to discard the worse approximations. In this paper the target was to classify all the corrected RCMs simulations according to their capacity to reproduce the historical statistics. On the other hand, the proposed method also considers hydrological statistics, including also droughts. We have demonstrated in a case study that the corrected RCM simulations that provide the best approximations of the meteorological statistics also provide the best approximations to the hydrology. 
250 Finally, we also showed that the best corrected RCMs to reproduce the climatic and hydrological conditions in the reference period may provide significant differences in the assessment of the future climate change impacts, due to the high uncertainty related with the RCM simulations of future potential scenarios (Sørland et al., 2018). Depending on the case study, the proposed analyses and classification (based on the reference period) can be used to identify the more reliable individual projections for the future period. It will allow us to define sets of selected individual projections to take into account future impacts uncertainty by considering the most "reliable" corrected RCMs (Pardo-Igúzquiza et al., 2019). It also allows to define ensemble of scenarios defined by the selected corrected RCMs simulations, which could produce more robust climate scenarios than those based on single projections (Fowler et al., 2007).

\section{Conclusions}

In this study we proposed a method to classify the corrected RCM simulations according to its capacity to reproduce the historical statistic. It considers basic (mean, standard deviation, and asymmetry coefficient) and drought statistics (frequency, length, magnitude, and intensity) of the meteorological and hydrological series, and could be applied to any case study. We also demonstrate that the corrected RCM simulations that provide the best approximations of the meteorology provide the best assessments of hydrological impacts.

The two best classified corrected RCM simulations were used to generate potential local scenarios of precipitation, 265 temperature and streamflow by using a lumped hydrological model. These projections were used to assess the impacts of climate change on local meteorology and hydrology within the Cenajo basin (southeast Spain). We analyzed the change in basic and drought statistics. The selection of corrected RCMs simulations predict significant future impacts on mean precipitation (-31.6 and $-44.0 \%$ ) and increase of mean temperature (26.0 and $32.2 \%)$. They also predict higher frequency (from 5 to 20 and 22 events of droughts), length (from 4.8 to 7.4 and 10.5 months), magnitude (from 2.53 to 6.56 and 9.62

270 SPI) and intensity (from 0.48 to 1.00 and 0.94 SPI) of extreme meteorological droughts. These changes are also propagated to the hydrological droughts. The studied area is located in the headwaters of the Segura River whose basin is an example of a Mediterranean area with a significant water demand, mainly for irrigation but also for urban supply, and low availability or resources. In these places methodologies to assess impacts of climate change on droughts are useful tools for water resources policy and decision makers.

\section{Funding}

This research was partially supported by the research project SIGLO-AN (RTI2018-101397-B-I00) from the Spanish Ministry of Science, Innovation and Universities (Programa Estatal de I+D+I orientada a los Retos de la Sociedad). 


\section{Acknowledgments}

We would like to thank the Spain02 and CORDEX projects for the data provided and the open-source R package qmap.

\section{References}

AEMET (Spanish Meteorologial Agency). Generación de Escenarios Regionalizados de Cambio Climático Para España; Agencia Estatal de Meteorología (Ministerio de Medio Ambiente y Medio Rural y Marino): Madrid, Spain, 2009.

Bonaccorso, B., Bordi, I., Cancelliere, A., Rossi, G., and Sutera, A.: Spatial variability of drought: An analysis of the SPI in Sicily, Water Resour. Manag., https://doi.org/10.1023/A:1024716530289, 2003.

Cramer, W., Guiot, J., Fader, M., Garrabou, J., Gattuso, J. P., Iglesias, A., Lange, M. A., Lionello, P., Llasat, M. C., Paz, S., Peñuelas, J., Snoussi, M., Toreti, A., Tsimplis, M. N., and Xoplaki, E.: Climate change and interconnected risks to sustainable development in the Mediterranean, https://doi.org/10.1038/s41558-018-0299-2, 2018.

Collados-Lara, A. J., Pardo-Igúzquiza, E., and Pulido-Velazquez, D.: A distributed cellular automata model to simulate potential future impacts of climate change on snow cover area, Adv. Water Resour., https://doi.org/10.1016/j.advwatres.2018.12.010, 2019.

Collados-Lara, A. J., Pulido-Velazquez, D., and Pardo-Igúzquiza, E.: An integrated statistical method to generate potential future climate scenarios to analyse droughts, https://doi.org/10.3390/w10091224, 2018.

Collados-Lara, A. J., Pulido-Velazquez, D., and Pardo-Iguzquiza, E.: A Statistical Tool to Generate Potential Future Climate Scenarios for Hydrology Applications, Sci. Program., https://doi.org/10.1155/2020/8847571, 2020.

CORDEX PROJECT. The Coordinated Regional Climate Downscaling Experiment CORDEX. Program Sponsored byWorld Climate Research Program (WCRP). 2013. Available online: http://www.cordex.org/ (accessed on 10 September 2020).

Cook, B. I., Miller, R. L., and Seager, R.: Dust and sea surface temperature forcing of the 1930s "Dust Bowl" drought, Geophys. Res. Lett., https://doi.org/10.1029/2008GL033486, 2008.

Fowler, H. J., Ekström, M., Blenkinsop, S., and Smith, A. P.: Estimating change in extreme European precipitation using a multimodel ensemble, J. Geophys. Res. Atmos., https://doi.org/10.1029/2007JD008619, 2007.

Gudmundsson, L., Bremnes, J. B., Haugen, J. E., and Engen-Skaugen, T.: Technical Note: Downscaling RCM precipitation to the station scale using statistical transformations \&ndash; A comparison of methods, Hydrol. Earth Syst. Sci., https://doi.org/10.5194/hess-16-3383-2012, 2012.

González, J. and Valdés, J. B.: New drought frequency index: Definition and comparative performance analysis, Water 305 Resour. Res., https://doi.org/10.1029/2005WR004308, 2006. 
Hanel, M., Rakovec, O., Markonis, Y., Máca, P., Samaniego, L., Kyselý, J., and Kumar, R.: Revisiting the recent European droughts from a long-term perspective, https://doi.org/10.1038/s41598-018-27464-4, 2018.

Heim, R. R.: A review of twentieth-century drought indices used in the United States, https://doi.org/10.1175/15200477(2002)083<1149:AROTDI>2.3.CO;2, 2002.

310 Herrera, S., Gutiérrez, J. M., Ancell, R., Pons, M. R., Frías, M. D., and Fernández, J.: Development and analysis of a 50-year high-resolution daily gridded precipitation dataset over Spain (Spain02), Int. J. Climatol., https://doi.org/10.1002/joc.2256, 2012.

Hollinger, S. E., Isard, S. A., and Welford, M. R. A new soil moisture drought index (SMDI) for predicting crop yields. Preprints Eight Conference on Applied Climatology, American Meteorological Society’s Preprints, Anaheim, CA; 187-190, 1993

Kogan, F. and Guo, W.: Early twenty-first-century droughts during the warmest climate, Geomatics, Nat. Hazards Risk, https://doi.org/10.1080/19475705.2013.878399, 2016.

Lazoglou, G., Angnostopoulou, C., Tolika, K., and Benedikt, G.: Evaluation of a new statistical method-TIN-copula-for the bias correction of climate models' extreme parameters, Atmosphere (Basel)., https://doi.org/10.3390/atmos11030243, 2020.

Liu, H., Chen, J., Zhang, X. C., Xu, C. Y., and Hui, Y.: A Markov chain-based bias correction method for simulating the temporal sequence of daily precipitation, Atmosphere (Basel)., https://doi.org/10.3390/atmos11010109, 2020.

Liu, W. T. and Kogan, F. N.: Monitoring regional drought using the vegetation condition index, Int. J. Remote Sens., https://doi.org/10.1080/01431169608949106, 1996.

Livada, I. and Assimakopoulos, V. D.: Spatial and temporal analysis of drought in Greece using the Standardized

Precipitation Index (SPI), Theor. Appl. Climatol., https://doi.org/10.1007/s00704-005-0227-z, 2007.

Lloyd-Hughes, B., Shaffrey, L. C., Vidale, P. L., and Arnell, N. W.: An evaluation of the spatiotemporal structure of largescale European drought within the HiGEM climate model, Int. J. Climatol., https://doi.org/10.1002/joc.3570, 2013.

Marcos-Garcia, P., Lopez-Nicolas, A., and Pulido-Velazquez, M.: Combined use of relative drought indices to analyze climate change impact on meteorological and hydrological droughts in a Mediterranean basin, J. Hydrol., https://doi.org/10.1016/j.jhydrol.2017.09.028, 2017.

McKee, T. B., Nolan, J., and Kleist, J.: The relationship of drought frequency and duration to time scales, Prepr. Eighth Conf. Appl. Climatol. Amer. Meteor, Soc., 1993.

McKee T.B., Doesken N.J., K. J.: Drought monitoring with multiple time scales, Proc. 9th Conf. Appl. Climatol., 1995.

Mishra, A. K. and Singh, V. P.: A review of drought concepts, https://doi.org/10.1016/j.jhydrol.2010.07.012, 2010. 
Mishra, A. K. and Singh, V. P.: Drought modeling - A review, https://doi.org/10.1016/j.jhydrol.2011.03.049, 2011.

Mishra, A. K., Singh, V. P., and Desai, V. R.: Drought characterization: A probabilistic approach, Stoch. Environ. Res. Risk Assess., https://doi.org/10.1007/s00477-007-0194-2, 2009.

Palmer, W. .: Meteorological Drought, Office of Climatology., US Weather Bureau, 1965.

Palmer, W. C.: Keeping Track of Crop Moisture Conditions, Nationwide: The New Crop Moisture Index, https://doi.org/10.1080/00431672.1968.9932814, 1968.

Pardo-Igúzquiza, E., Collados-Lara, A. J., and Pulido-Velazquez, D.: Estimation of the spatiotemporal dynamics of snow covered area by using cellular automata models, J. Hydrol., https://doi.org/10.1016/j.jhydrol.2017.04.058, 2017.

Pardo-Igúzquiza, E., Collados-Lara, A. J., and Pulido-Velazquez, D.: Potential future impact of climate change on recharge in the Sierra de las Nieves (southern Spain) high-relief karst aquifer using regional climate models and statistical corrections, Environ. Earth Sci., https://doi.org/10.1007/s12665-019-8594-4, 2019.

Pedro-Monzonís, M., Solera, A., Ferrer, J., Estrela, T., and Paredes-Arquiola, J.: A review of water scarcity and drought indexes in water resources planning and management, J. Hydrol., https://doi.org/10.1016/j.jhydrol.2015.05.003, 2015.

Pérez-Sánchez, J., Senent-Aparicio, J., Segura-Méndez, F., Pulido-Velazquez, D., and Srinivasan, R.: Evaluating hydrological models for deriving water resources in peninsular Spain, Sustain., https://doi.org/10.3390/su11102872, 2019.

Pulido-Velazquez, D., Ahlfeld, D., Andreu, J., and Sahuquillo, A.: Reducing the computational cost of unconfined groundwater flow in conjunctive-use models at basin scale assuming linear behaviour: The case of Adra-Campo de Dalías, J. Hydrol., https://doi.org/10.1016/j.jhydrol.2008.02.006, 2008.

Pulido-Velazquez, D., Collados-Lara, A. J., and Alcalá, F. J.: Assessing impacts of future potential climate change scenarios on aquifer recharge in continental Spain, J. Hydrol., https://doi.org/10.1016/j.jhydrol.2017.10.077, 2018.

Pulido-Velazquez, D., Renau-Pruñonosa, A., Llopis-Albert, C., Morell, I., Collados-Lara, A. J., Senent-Aparicio, J., and Baena-Ruiz, L.: Integrated assessment of future potential global change scenarios and their hydrological impacts in coastal aquifers - A new tool to analyse management alternatives in the Plana Oropesa-Torreblanca aquifer, Hydrol. Earth Syst. Sci., https://doi.org/10.5194/hess-22-3053-2018, 2018.

Seager, R., Burgman, R., Kushnir, Y., Clement, A., Cook, E., Naik, N., and Miller, J.: Tropical pacific forcing of North

American medieval megadroughts: Testing the concept with an atmosphere model forced by coral-reconstructed SSTs, J. Clim., https://doi.org/10.1175/2008JCLI2170.1, 2008.

Shrestha, M., Acharya, S. C., and Shrestha, P. K.: Bias correction of climate models for hydrological modelling - are simple methods still useful?, Meteorol. Appl., https://doi.org/10.1002/met.1655, 2017. 
Sørland, S. L., Schär, C., Lüthi, D., and Kjellström, E.: Bias patterns and climate change signals in GCM-RCM model

chains, Environ. Res. Lett., https://doi.org/10.1088/1748-9326/aacc77, 2018.

Témez, J. R.: Modelo Matemático de Transformación "Precipitación-Aportación”; Asociación de Investigación Industrial Eléctrica (ASINEL): Madrid, Spain, 1977.

Teutschbein, C. and Seibert, J.: Bias correction of regional climate model simulations for hydrological climate-change impact studies: Review and evaluation of different methods, J. Hydrol., https://doi.org/10.1016/j.jhydrol.2012.05.052, 2012.

370 Thornthwaite, C. W.: An approach towards a rational classification of climate. Geogr. Rev. 38, 55-94, 1948

Tramblay, Y., Koutroulis, A., Samaniego, L., Vicente-Serrano, S. M., Volaire, F., Boone, A., Le Page, M., Llasat, M. C., Albergel, C., Burak, S., Cailleret, M., Kalin, K. C., Davi, H., Dupuy, J. L., Greve, P., Grillakis, M., Hanich, L., Jarlan, L., Martin-StPaul, N., Martínez-Vilalta, J., Mouillot, F., Pulido-Velazquez, D., Quintana-Seguí, P., Renard, D., Turco, M., Türkeş, M., Trigo, R., Vidal, J. P., Vilagrosa, A., Zribi, M., and Polcher, J.: Challenges for drought assessment in the 375 Mediterranean region under future climate scenarios, https://doi.org/10.1016/j.earscirev.2020.103348, 2020.

Vicente-Serrano, S. M., Tomas-Burguera, M., Beguería, S., Reig, F., Latorre, B., Peña-Gallardo, M., Luna, M. Y., Morata, A., and González-Hidalgo, J. C.: A high resolution dataset of drought indices for Spain, https://doi.org/10.3390/data2030022, 2017.

Zhang, X., Tang, Q., Liu, X., Leng, G., and Li, Z.: Soil moisture drought monitoring and forecasting using satellite and 
https://doi.org/10.5194/nhess-2021-121

Preprint. Discussion started: 23 April 2021

(c) Author(s) 2021. CC BY 4.0 License.

(c) (1)

Table 1: Regional and Global climate models considered.

\begin{tabular}{lll}
\cline { 2 - 3 } & RCM & Nested to GCM \\
\hline RCM1 & CCLM4-8-17 & CNRM-CM5 \\
RCM2 & CCLM4-8-17 & EC-EARTH \\
RCM3 & CCLM4-8-17 & MPI-ESM-LR \\
RCM4 & HIRHAM5 & EC-EARTH \\
RCM5 & RACMO22E & EC-EARTH \\
RCM6 & RCA4 & CNRM-CM5 \\
RCM7 & RCA4 & EC-EARTH \\
RCM8 & RCA4 & MPI-ESM-LR \\
RCM9 & WRF331F & IPSL-CM5A-MR \\
\hline
\end{tabular}

395 Table 2: Classification of corrected RCMs according their reliability considering basic (mean, standard deviation and asymmetry coefficient) and droughts statistics (frequency, length, magnitude and intensity) for the meteorological and hydrological analyses. Lower numbers represent a higher reliability.

\begin{tabular}{lcc}
\cline { 2 - 3 } & \multicolumn{2}{c}{$\begin{array}{c}\text { Statistics used in the classification } \\
\text { (basics and droughts) }\end{array}$} \\
\cline { 2 - 3 } & Meteorological & Hydrological \\
\hline RCM1 & 4 & 3 \\
RCM2 & 2 & 2 \\
RCM3 & 9 & 6 \\
RCM4 & 6 & 8 \\
RCM5 & 7 & 7 \\
RCM6 & 5 & 9 \\
RCM7 & 3 & 5 \\
RCM8 & 8 & 4 \\
RCM9 & 1 & 1 \\
\hline
\end{tabular}




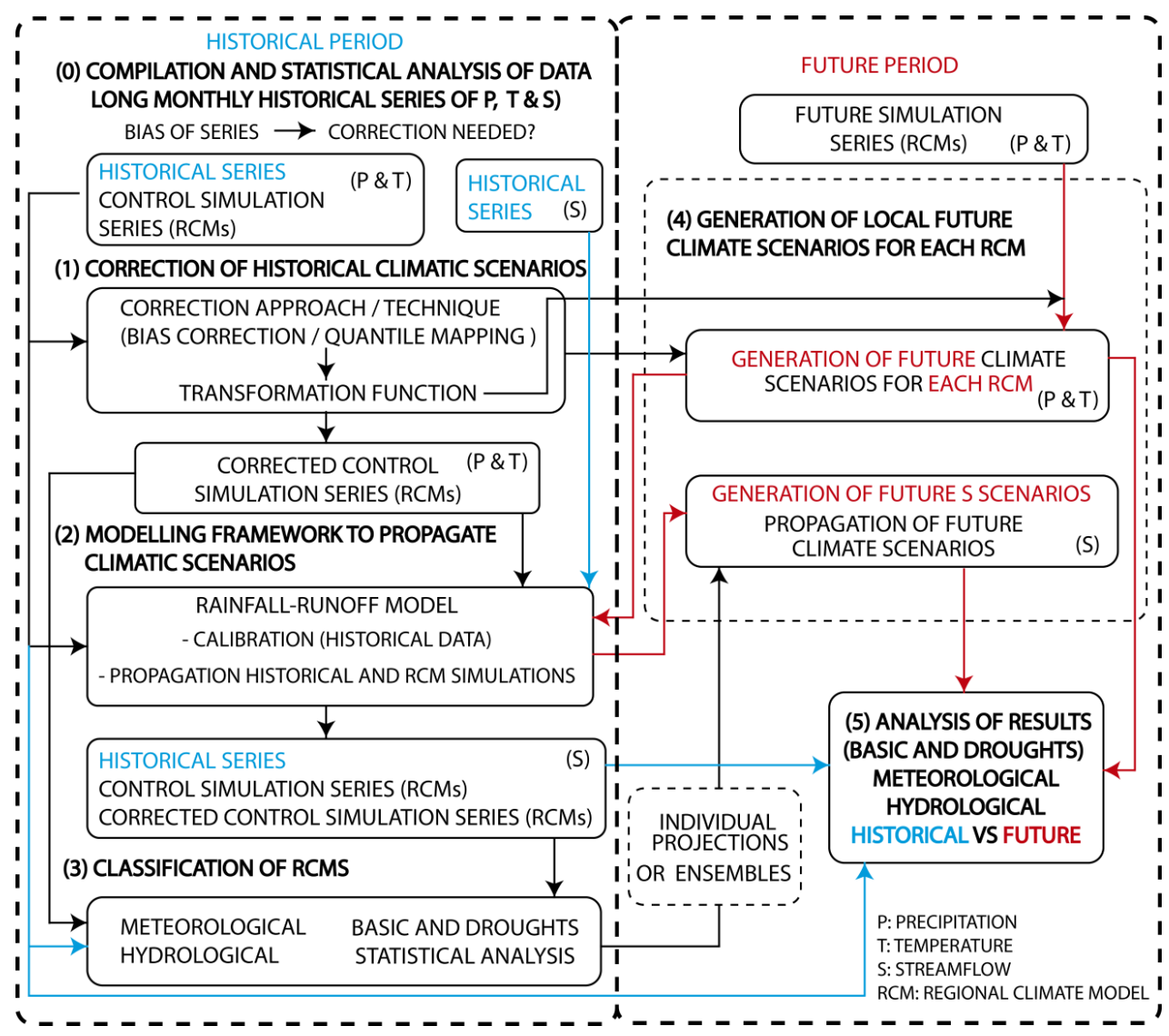

Figure 1: Flow chart of the proposed methodology for the assessment of future meteorological and hydrological droughts.

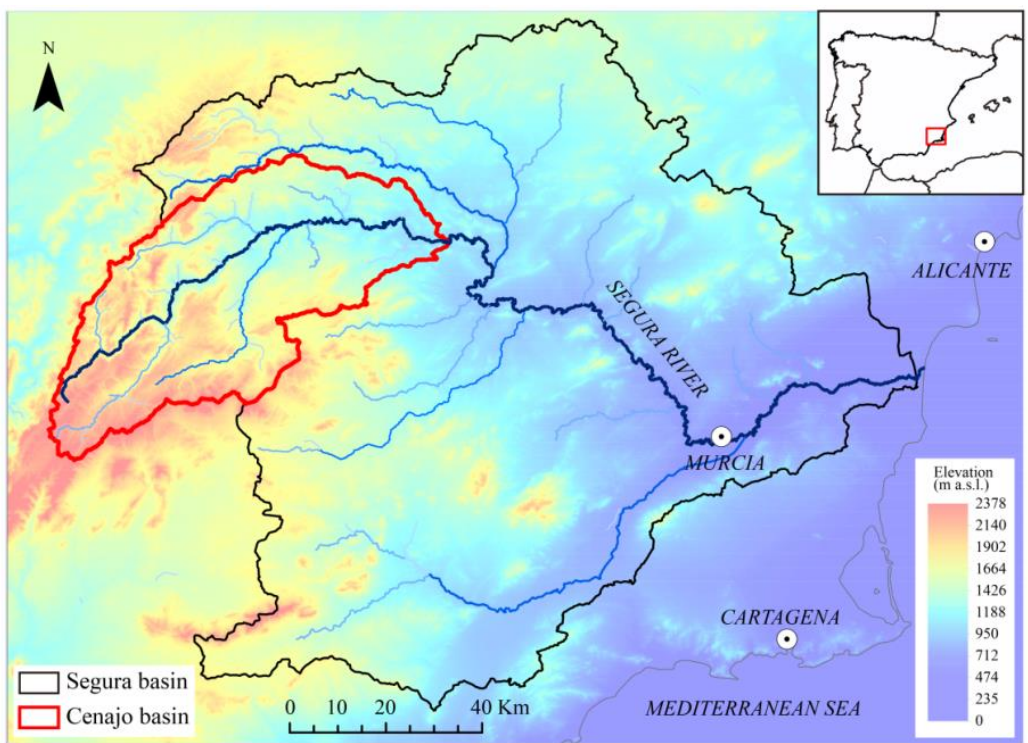

Figure 2: Location of the case study. 

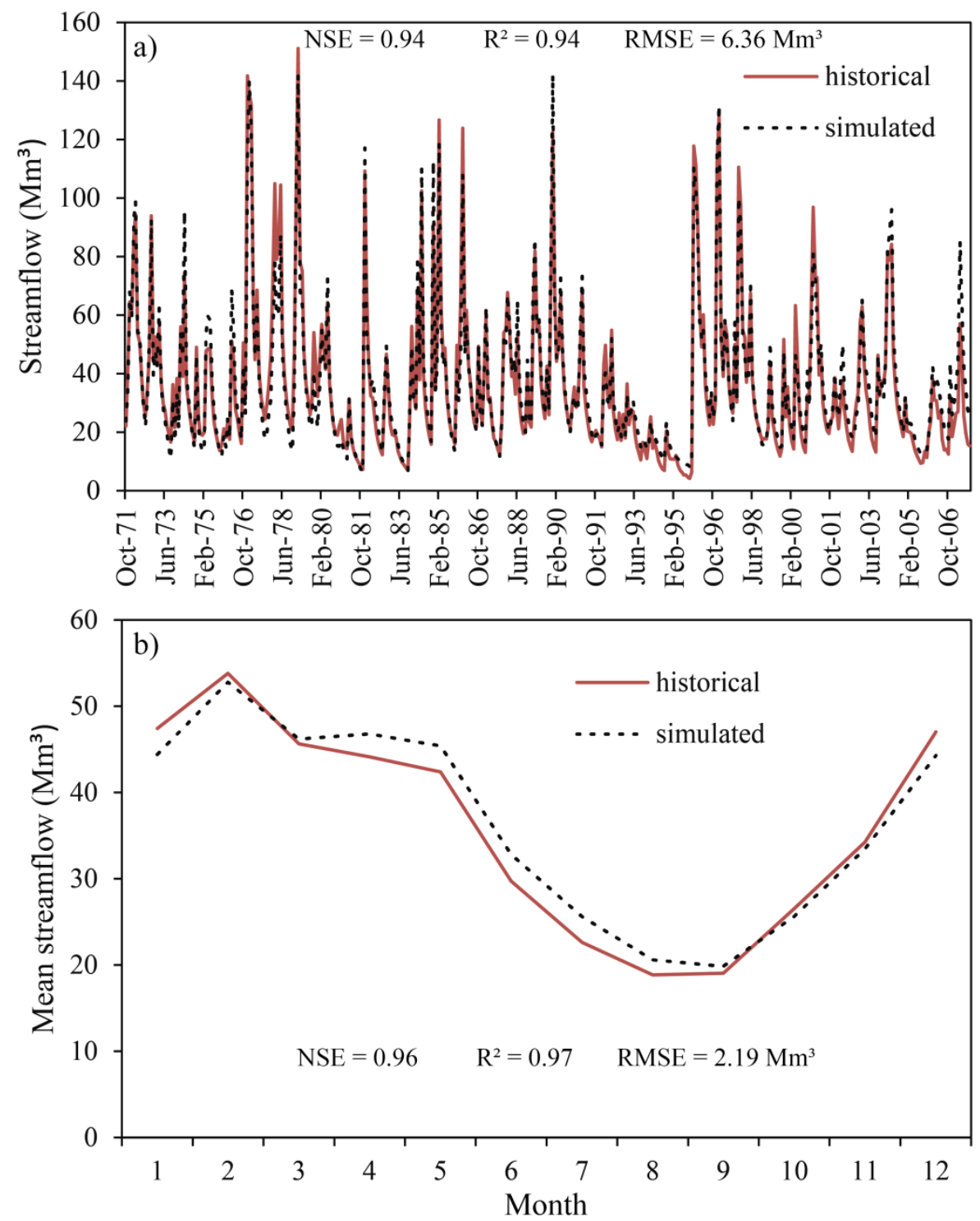

Figure 3: Historical and simulated monthly streamflow series in the Cenajo basin for the period (1971-2007) (a) and mean monthly values within the mean year of the cited period (b). 
https://doi.org/10.5194/nhess-2021-121

Preprint. Discussion started: 23 April 2021

(c) Author(s) 2021. CC BY 4.0 License.
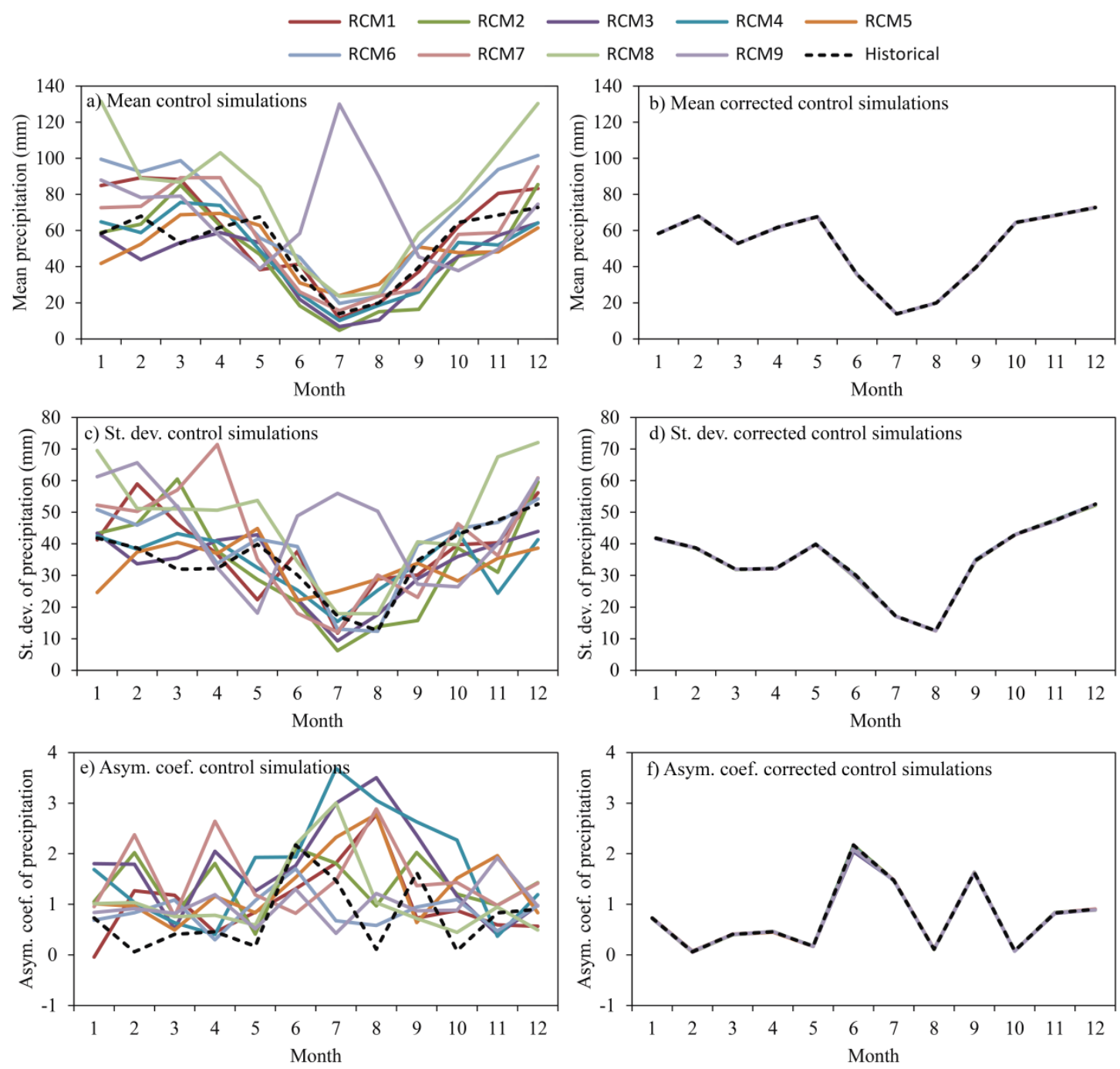

410 Figure 4: Monthly mean, standard deviation, and asymmetry coefficient of precipitation within the mean year of the period (19722001) for the historical and control simulation series (left column) and historical and corrected control simulation series (right column). 
https://doi.org/10.5194/nhess-2021-121

Preprint. Discussion started: 23 April 2021

(c) Author(s) 2021. CC BY 4.0 License.
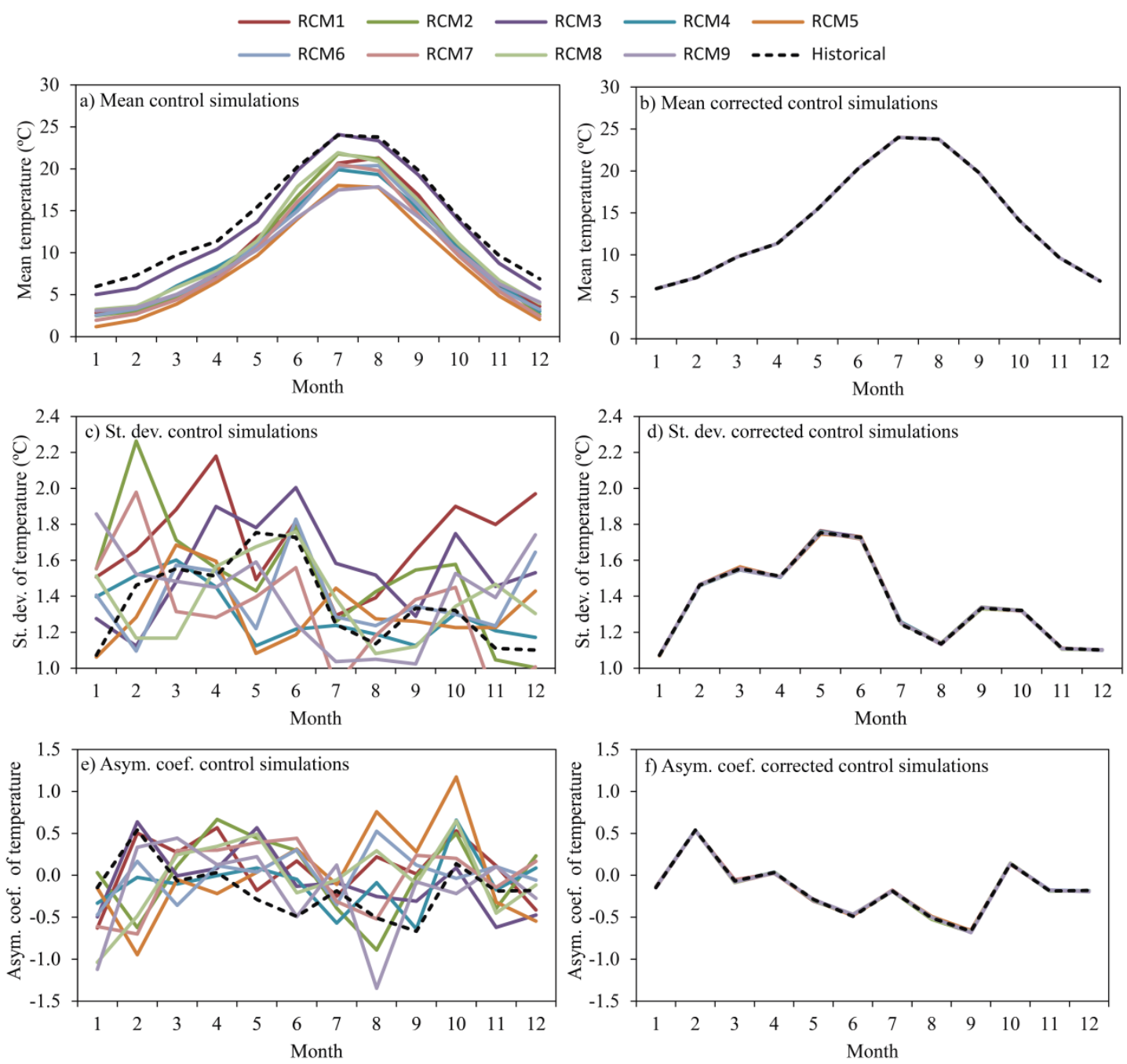

Figure 5: Monthly mean temperature, standard deviation, and asymmetry coefficient of temperature within the mean year of the period (1972-2001) for the historical and control simulation series (left column) and historical and corrected control simulation series (right column). 
https://doi.org/10.5194/nhess-2021-121

Preprint. Discussion started: 23 April 2021

(c) Author(s) 2021. CC BY 4.0 License.
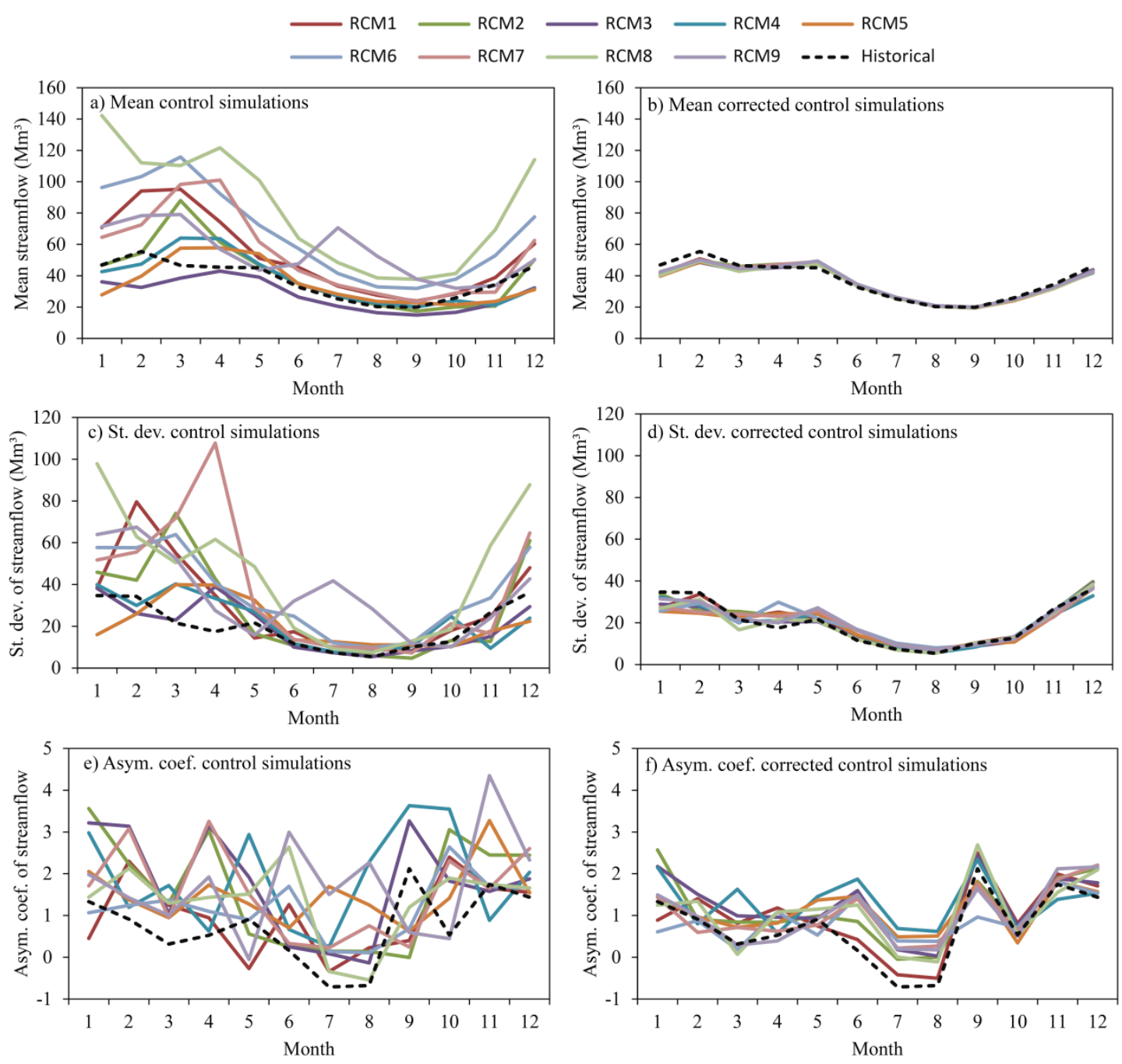

Figure 6: Monthly mean, standard deviation, and asymmetry coefficient of streamflow within the mean year of the period (19722001) for the historical and control simulation series (left column) and historical and corrected control simulation series (right column). 

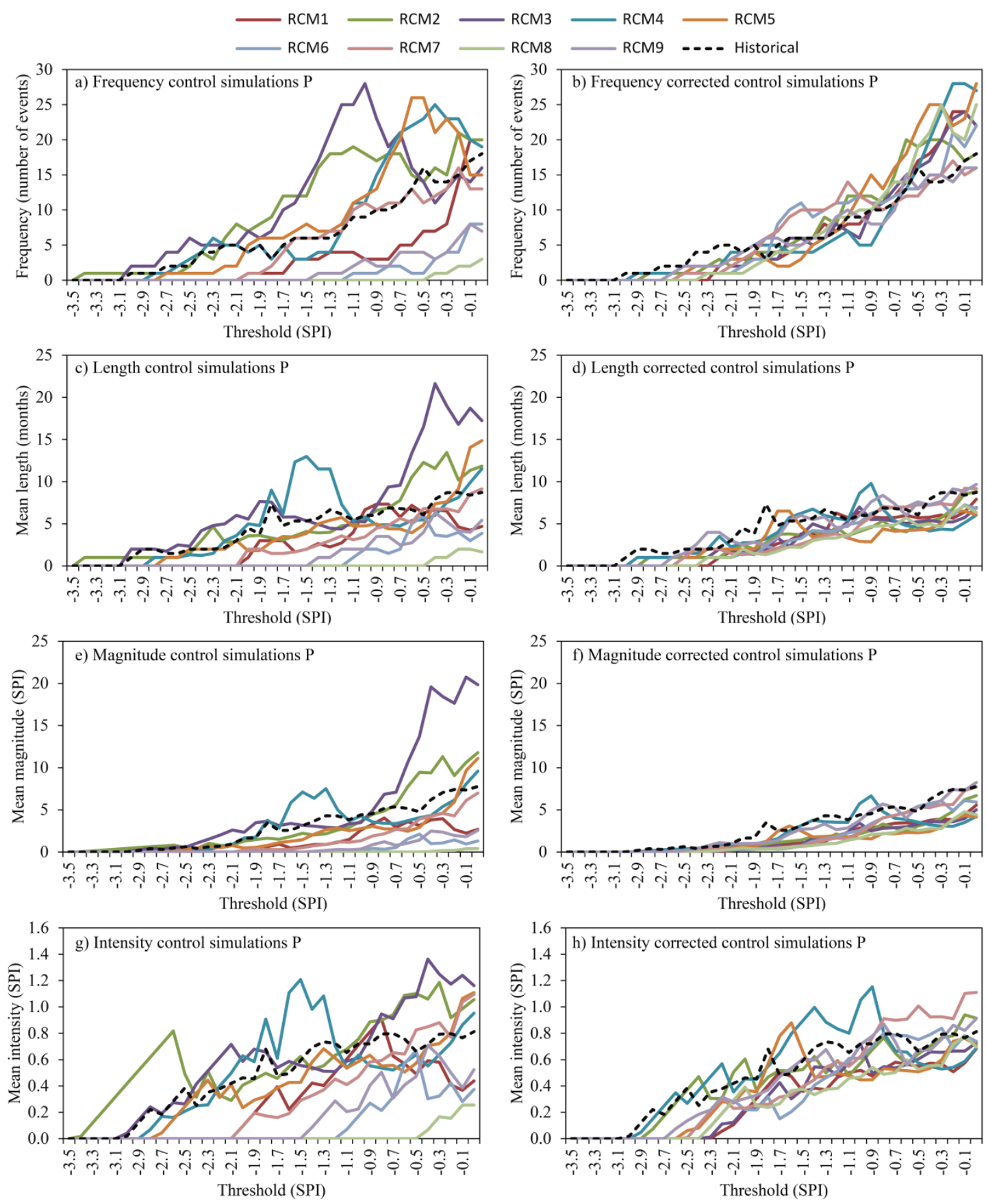

Figure 7: Drought statistics (frequency, length, magnitude and intensity) of the period (1972-2001) for the historical and control simulation series (left column) and historical and corrected control simulation series (right column) for precipitation (meteorological droughts). 

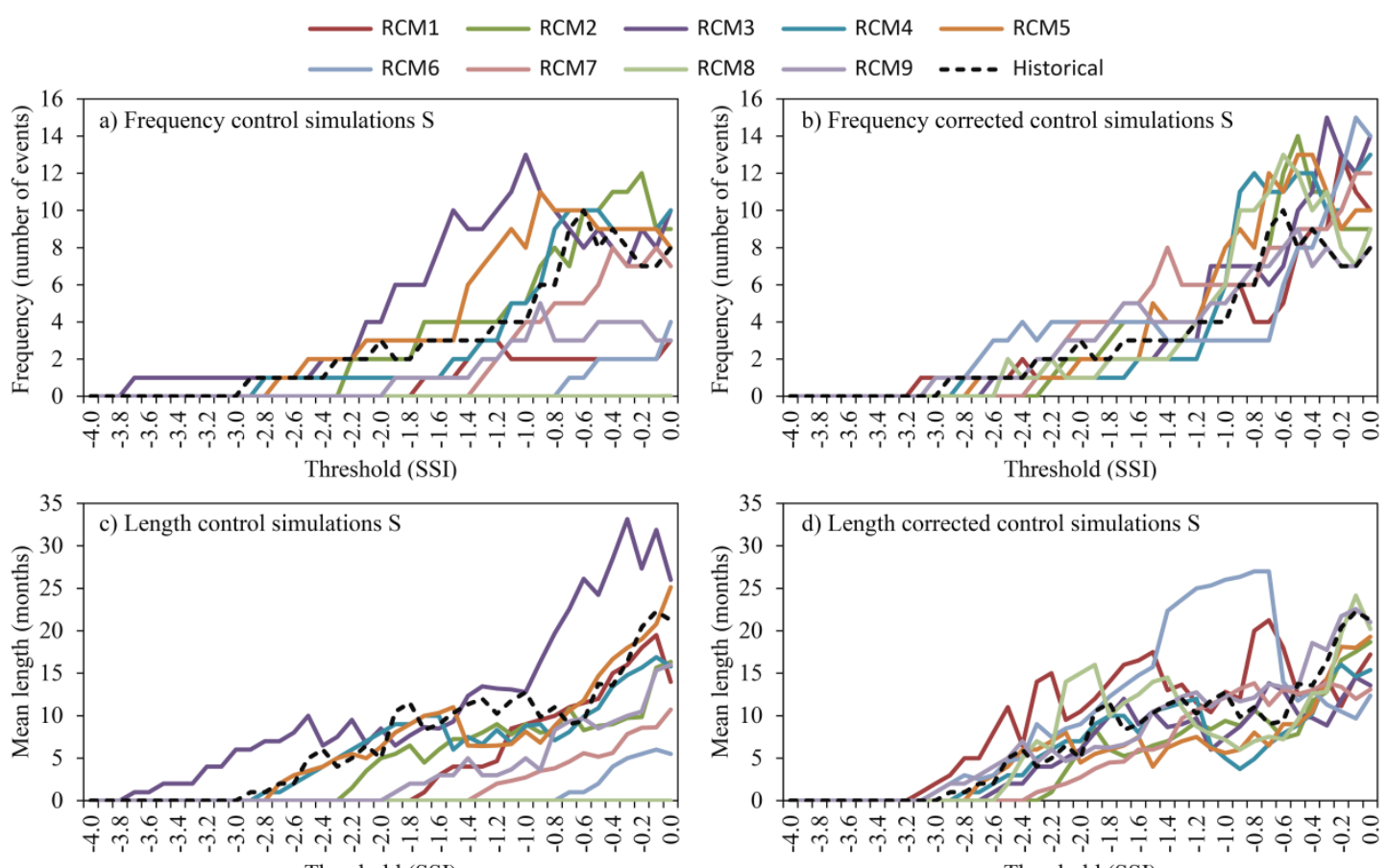

Threshold (SSI)
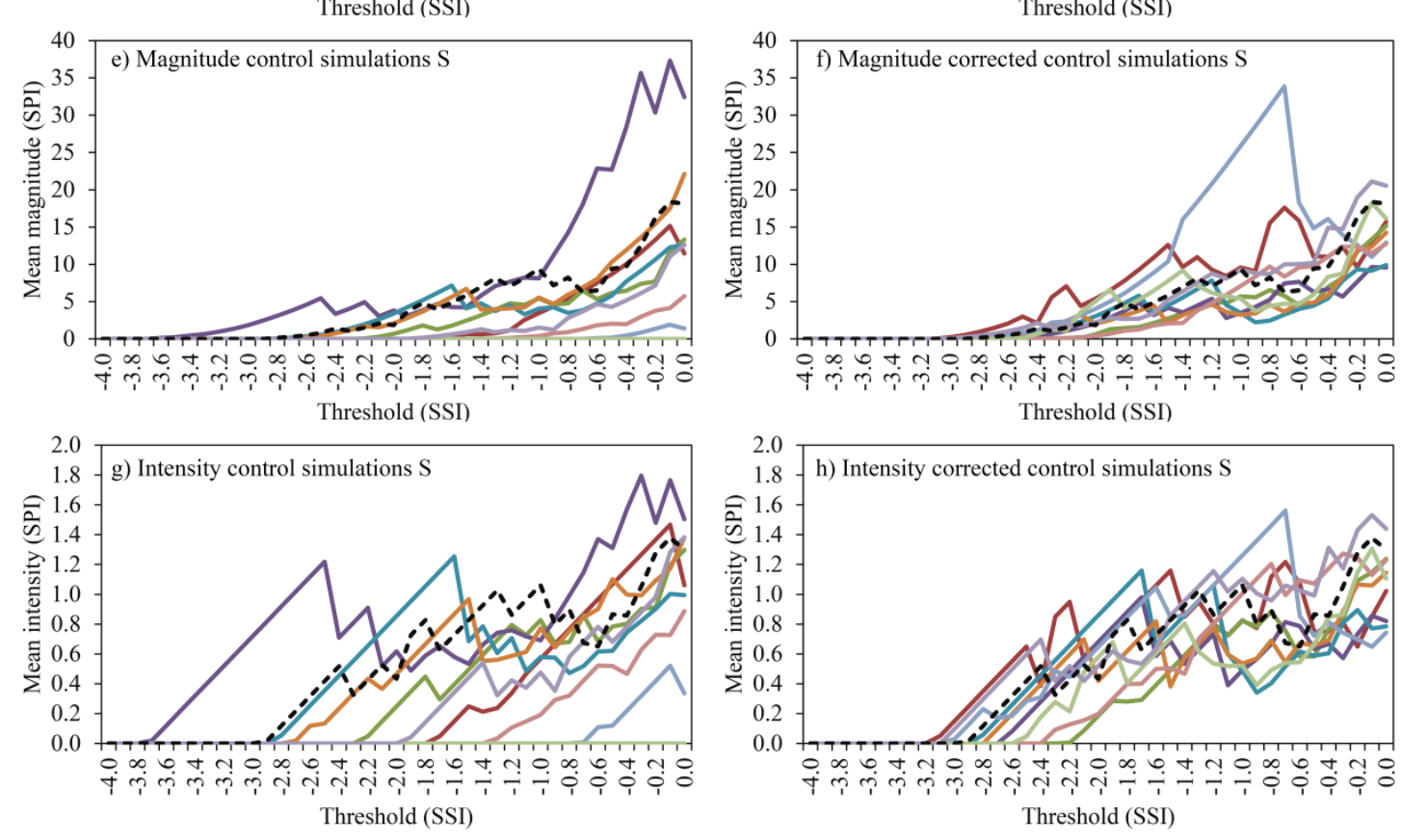

Figure 8: Drought statistics (frequency, length, magnitude and intensity) of the period (1972-2001) for the historical and control simulation series (left column) and historical and corrected control simulation series (right column) for streamflow (hydrological droughts). 
https://doi.org/10.5194/nhess-2021-121

Preprint. Discussion started: 23 April 2021

(c) Author(s) 2021. CC BY 4.0 License.

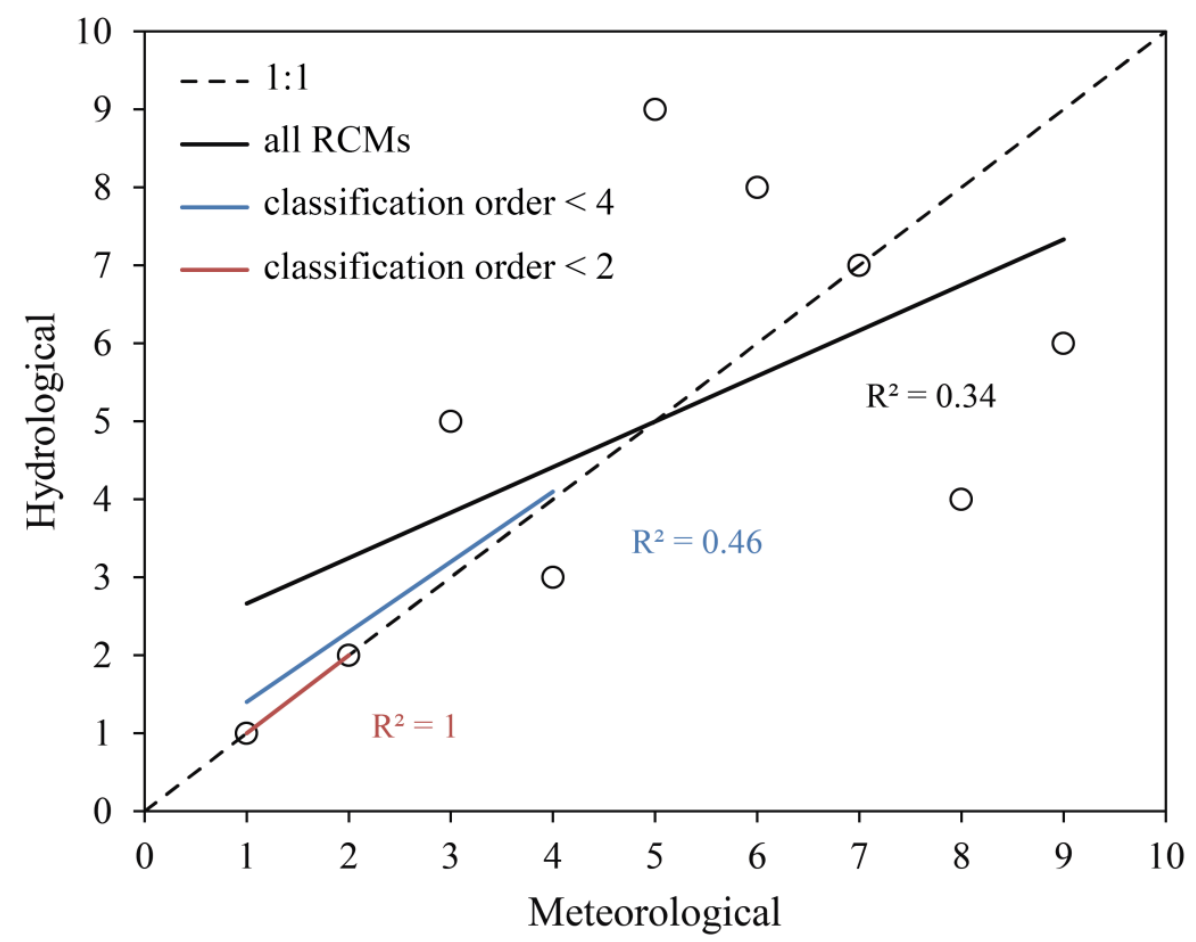

Figure 9: Correlations between the classifications of RCMs for the meteorological and hydrological analyses. 

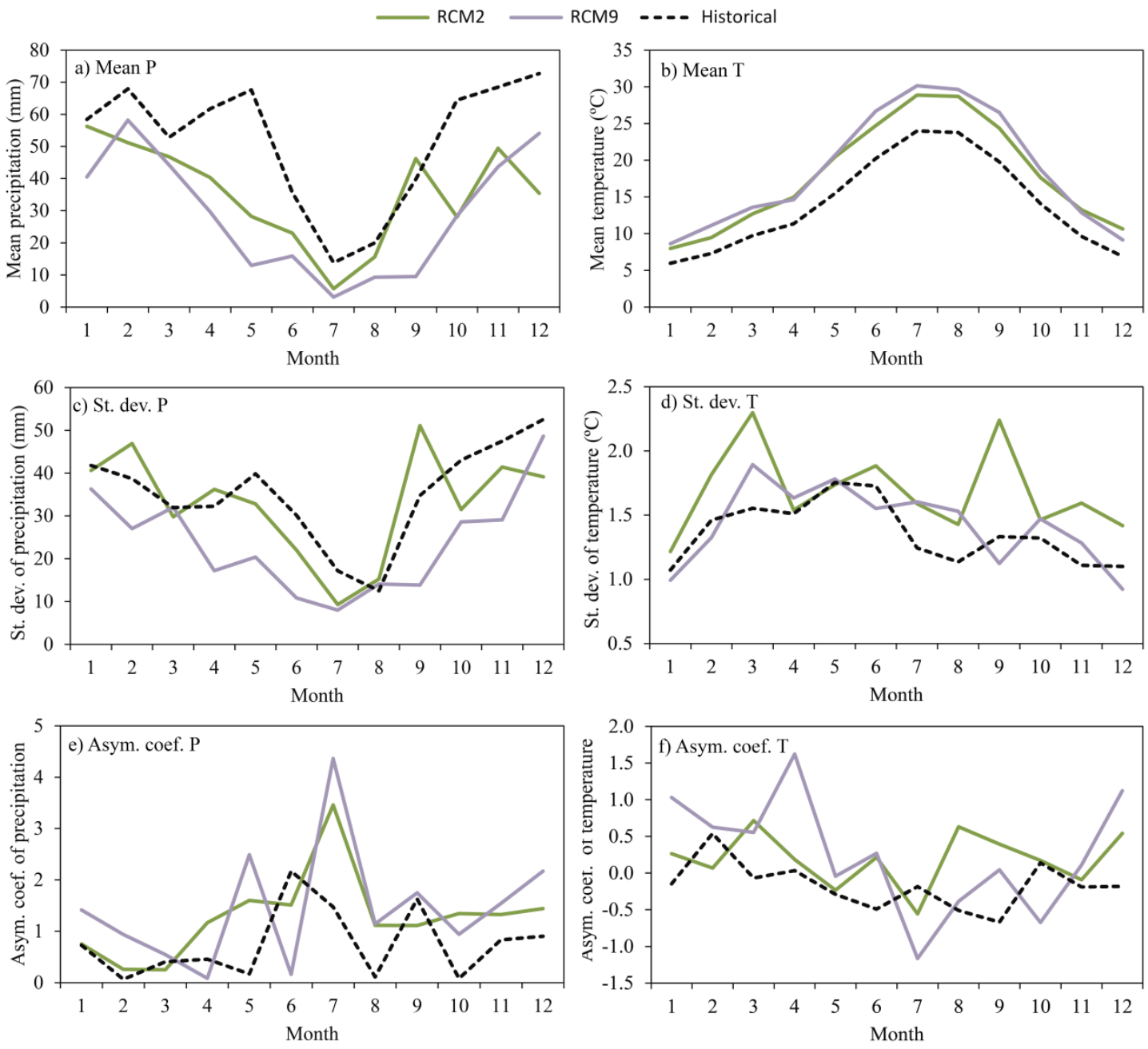

Figure 10: Monthly mean, standard deviation, and asymmetry coefficient within the mean year of the historical period (1972-2002) and future horizon (2071-2100) series (RCM 2 and 9) for precipitation (left column) and temperature (right column). 

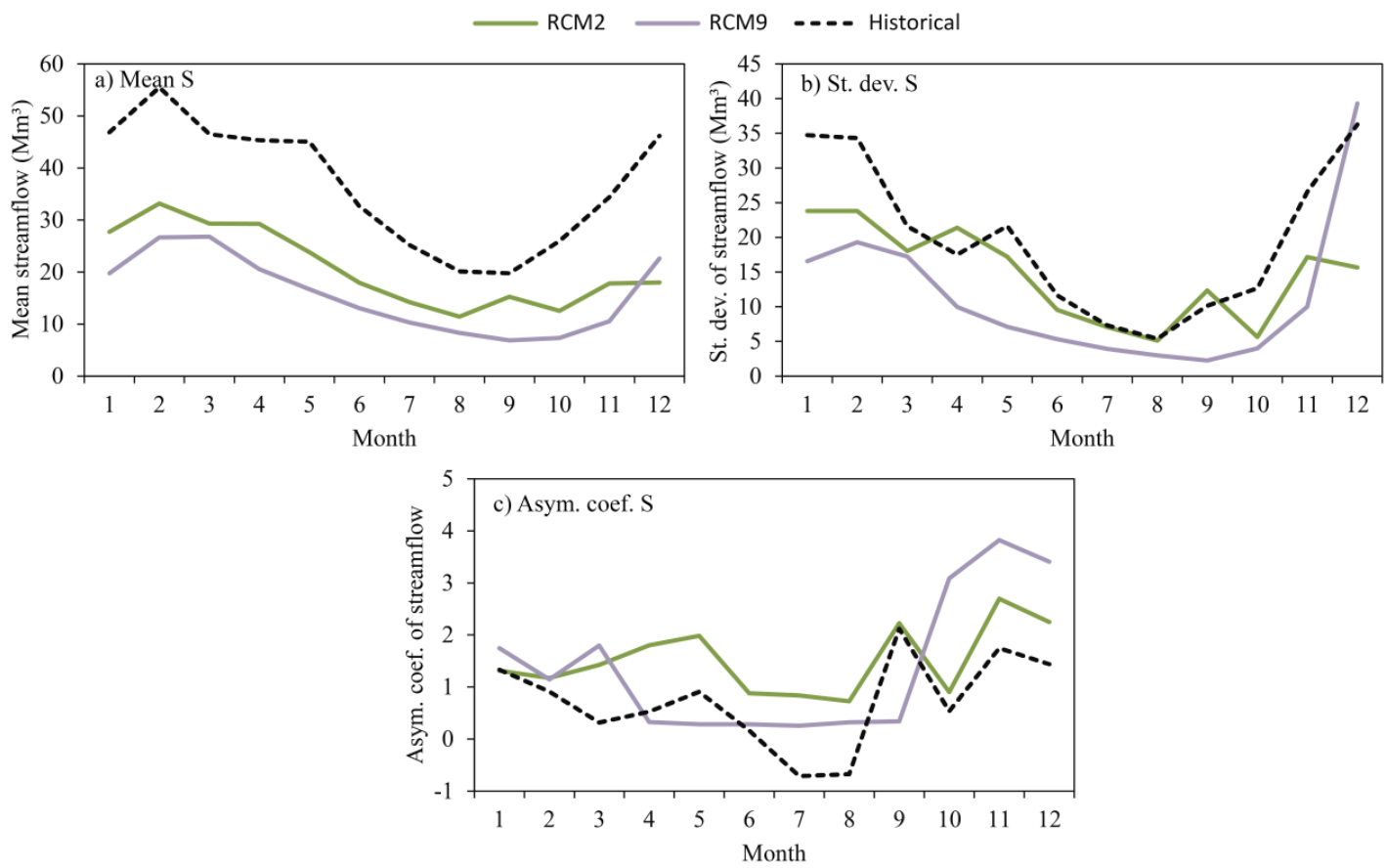

Figure 11: Monthly mean (a), standard deviation (b), and asymmetry coefficient (c) within the mean year of the historical period (1972-2002) and future horizon (2071-2100) series (RCM 2 and 9) for streamflow.

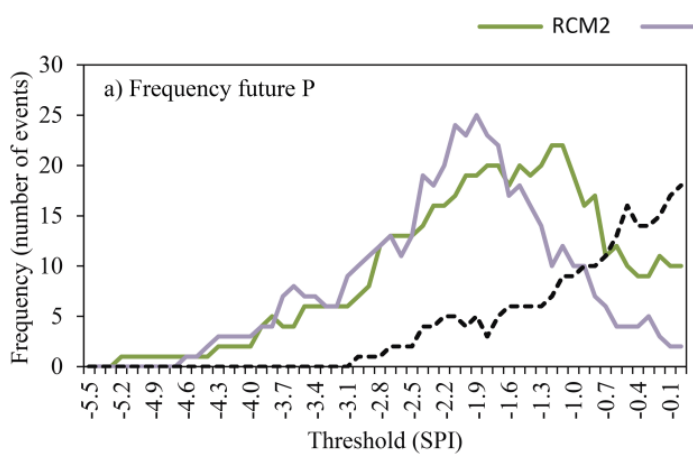

RCM9 -.- Historical
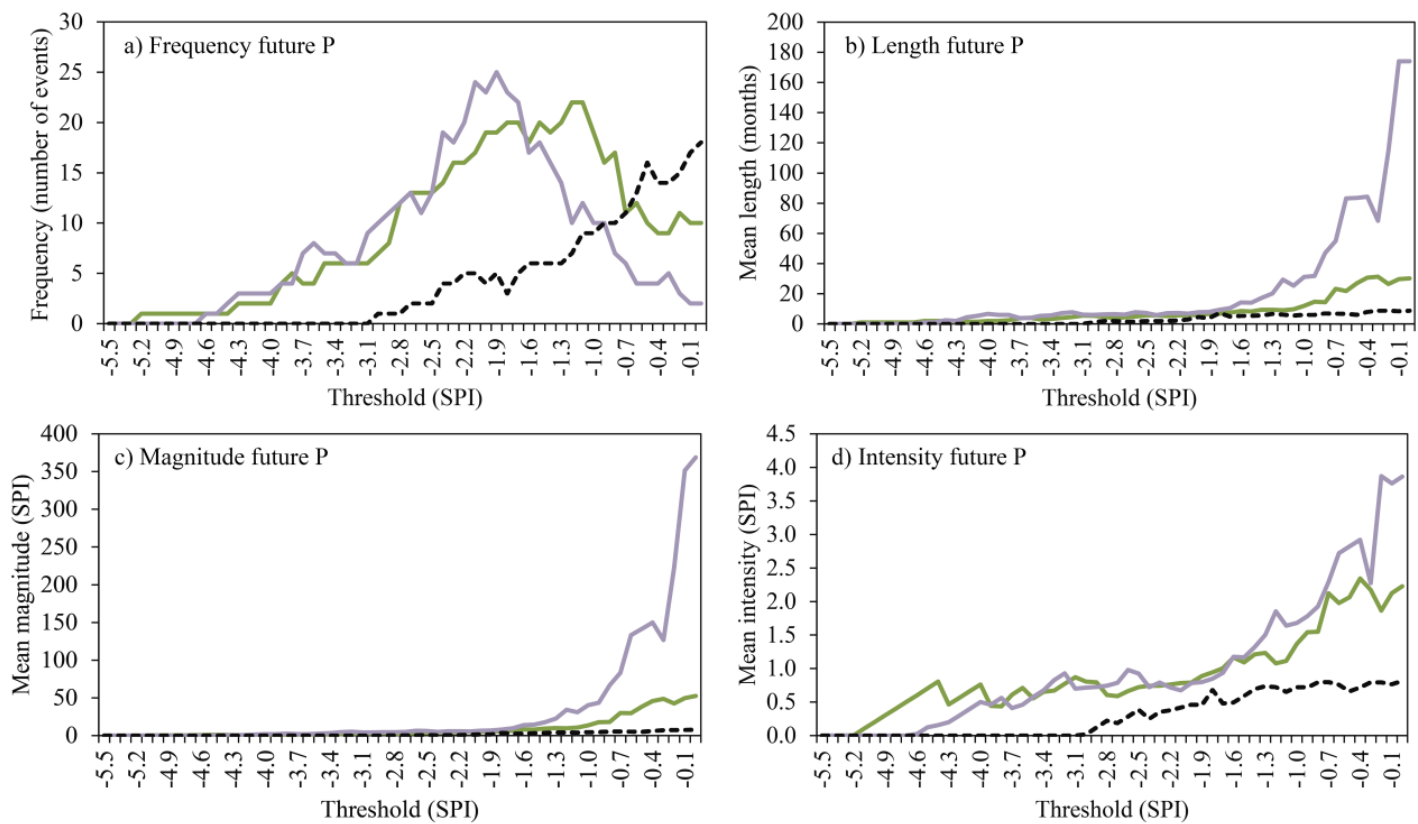

Figure 12: Drought statistics [a) frequency, b) length, c) magnitude, d) intensity] of the historical period (1972-2002) and future horizon (2071-2100) series (RCM 2 and 9) for precipitation (meteorological droughts). 
https://doi.org/10.5194/nhess-2021-121

Preprint. Discussion started: 23 April 2021

(c) Author(s) 2021. CC BY 4.0 License.

(c) (1)

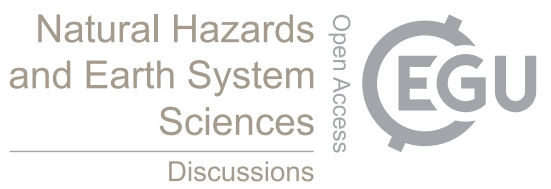

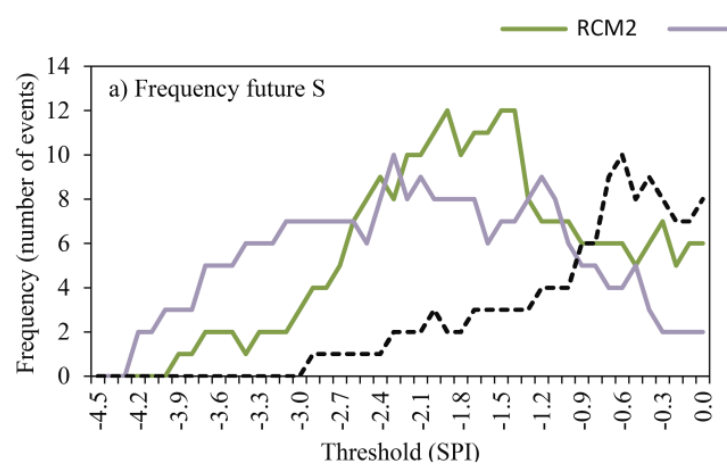
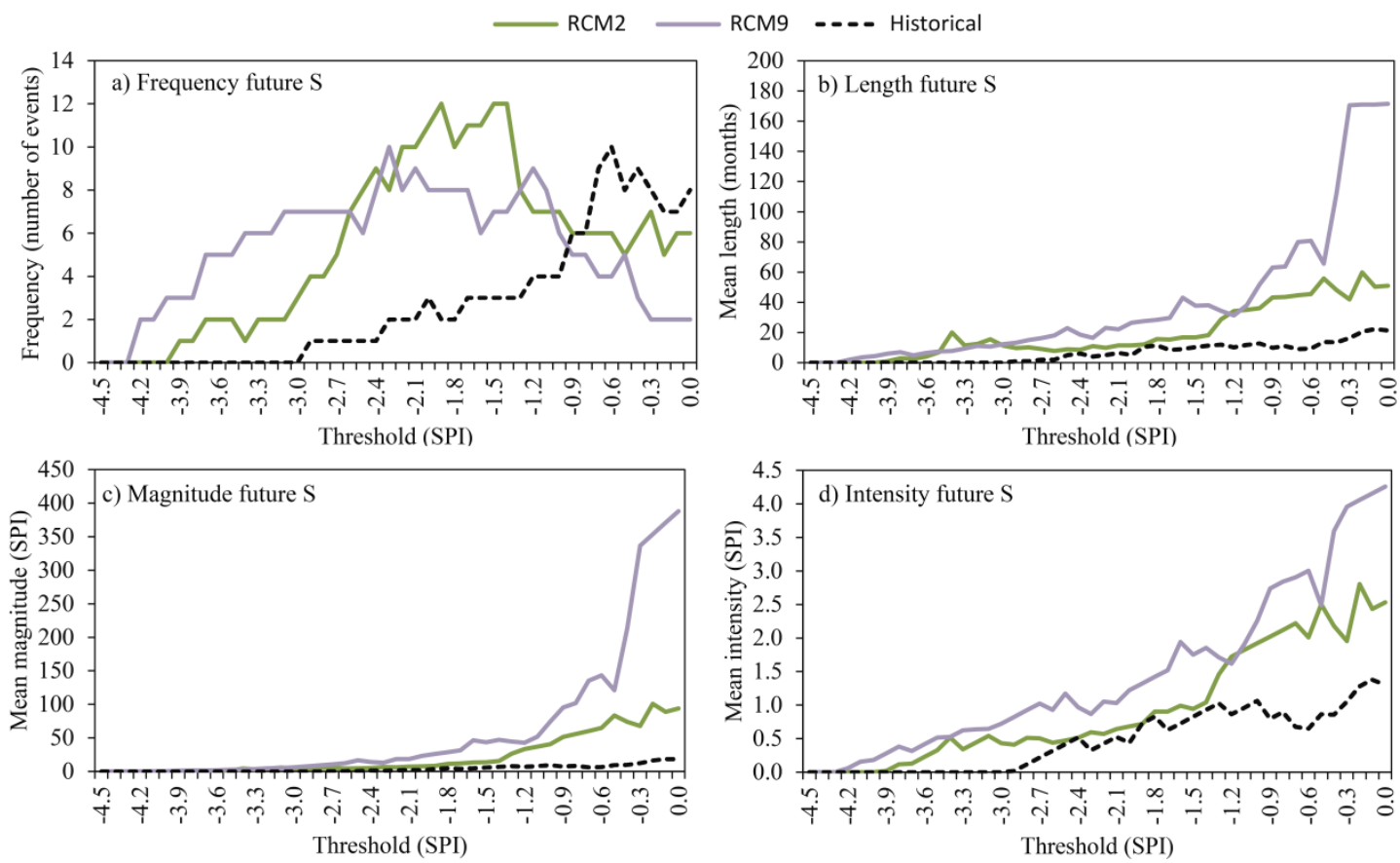

Figure 13: Drought statistics [a) frequency, b) length, c) magnitude, d) intensity] of the historical period (1972-2002) and future horizon (2071-2100) series (RCM 2 and 9) for streamflow (hydrological droughts). 